\title{
Correction to: Differences between sun and shade habitats on the invasive shrub Lantana camara and its biocontrol agent Teleonemia scrupulosa
}

Nic Venter ${ }^{1}$ D $\cdot$ Maurice Mkasi $^{1} \cdot$ Phuluso Mudau $^{1} \cdot$ Solomon W. Newete ${ }^{1,3} \cdot$ Blair W. Cowie $^{1,2} \cdot$ Ed T. F. Witkowski $^{1}$. Marcus J. Byrne ${ }^{1,2}$

Published online: 14 November 2019

(c) Springer Nature B.V. 2019

\section{Correction to: \\ Arthropod-Plant Interactions (2019) 13:885-893 \\ https://doi.org/10.1007/s11829-019-09713-z}

In the original publication of the article, the family name of the corresponding author was missed out. The correct author name is Nic Venter.

Publisher's Note Springer Nature remains neutral with regard to jurisdictional claims in published maps and institutional affiliations.

The original article can be found online at https://doi.org/10.1007/ s11829-019-09713-z.

Nic Venter

nic.venter@wits.ac.za

1 School of Animal, Plant and Environmental Sciences,

University of the Witwatersrand, Johannesburg, South Africa

2 DST-NRF Centre of Excellence for Invasion Biology, School of Animal, Plant and Environmental Sciences, University of the Witwatersrand, Johannesburg, South Africa

3 Geoinformation Science Programme, Agricultural Research Council - Institute for Soil, Climate and Water (ARC-ISCW), Pretoria, South Africa 